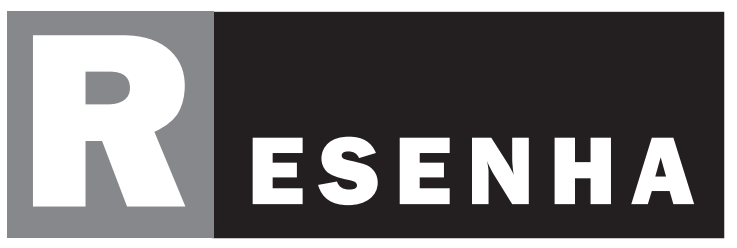




\title{
KHOTARI, Ashish; SALLEH, Ariel; ESCOBAR, Arturo; DEMARIA, Federico; ACOSTA, Alberto. Pluriverse: A Post-Development Dictionary. Nova Delhi: Tulika Books, 2019.
}

\section{Viviane Kraieski de Assunção}

Universidade do Extremo Sul Catarinense, Criciúma, Santa Catarina, Brasil

\section{Andréia Gimenes Amaro}

Universidade do Extremo Sul Catarinense, Criciúma, Santa Catarina, Brasil

\section{RESUMO}

Resenha da obra Pluriverse: a post-development dictionary, deAshish Khotari,Ariel Salleh, Arturo Escobar; Federico Demaria e Alberto Acosta. Acoletânea reúne mais de 100 verbetes de autores, escolhidos e convidados por serem pesquisadores e/ou ativistas engajados com lutas e movimentos sociais do Sul global, e comprometidos com uma perspectiva decolonial e crítica das estruturas do sistema capitalista, da modernidade ocidental e do patriarcado. A partir dessa linha, o livro propõe uma compilação de conceitos, visões de mundo e práticas que se opõem à ontologia eurocêntrica universalista, apresentando alternativas transformadorasparaos processos atualmentedominantes de desenvolvimento globalizado.

Palavras-chave: Resenha, Pós-Desenvolvimento, Decolonialidade, Anticapitalismo.

\begin{abstract}
Review of the book Pluriverse: a post-development dictionary, by Ashish Khotari, Ariel Salleh, Arturo Escobar and Federico Demaria and Alberto Acosta. The collection brings together more than 100 entries by authors, chosen and invited for being researchers and/or activists engaged in struggles and social movements in the global South, and committed to a decolonial and critical perspective of the structures of the capitalist system, western modernity and patriarchy. Based on this, the book proposes a compilation of concepts, worldviews and practices that oppose the universalist eurocentric ontology, presenting transforming alternatives to the currently dominant processes of globalized development.
\end{abstract}

Keywords: Review, Post-Development, Decoloniality, Anti-capitalism. 
Pluriverse: a post-development dictionary parte da noção zapatista de pluriverso para realizar uma severa crítica à noção de desenvolvimento e apontar caminhos para sua superação. A obra tem como epígrafe a Quarta Declaração da Selva Lacandona, do Exército Zapatista de Libertação Nacional (EZLN), de 1996, que, em um dos trechos, afirma: "In the world we want, everybody fits. The world we want is a world in which many words fit". Assim, a ideia de que não há um universo único, mas um mundo onde cabem muitos mundos, na tradução livre do texto, está articulada a um amplo inventário de propostas alinhadas a uma concepção de pós-desenvolvimento, segundo os próprios organizadores.

A obra é organizada pelo ambientalista indiano Ashish Khotari, a socióloga australiana Ariel Salleh, o antropólogo colombiano Arturo Escobar, o professor de economia espanhol Federico Demaria e o economista equatoriano Alberto Acosta, o que revela critérios para ser autor dos textos que compõem o livro. Segundo seus organizadores, os autores devem ser sujeitos - pesquisadores e ativistas - engajados com lutas e movimentos sociais do Sul global, e comprometidos com uma perspectiva decolonial e crítica das estruturas que promovem as injustiças sociais e ambientais, a saber, o sistema capitalista, a modernidade ocidental e o patriarcado. Cada verbete é escrito por autor profundamente envolvido com a visão de mundo e a prática descrita, "das resistências indígenas a rebeldes de classe média" (p. 18).

O livro propõe uma compilação de conceitos, visões de mundo e práticas que se opõem à ontologia eurocêntrica universalista. O prefácio e a introdução apresentam as intenções e as discussões teórico-epistemológicas que precederam a obra. Situam os debates críticos sobre desenvolvimento realizados por autores de textos que compõem a obra, como Vandana Shiva e Arturo Escobar ${ }^{1}$ além de outros, como Gilbert Rist e Wolfgang Sachs. Este último assina o prólogo, intitulado The Development Dictionary Revisited, uma referência ao The Development Dictionary (1993), obra organizada por Sachs, que expõe de forma crítica os conceitos-chaves do discurso do desenvolvimento, e decretam o fim de sua era. $\mathrm{O}$ autor reconhece a ingenuidade deste otimismo pós-Guerra Fria, e define o desenvolvimento como um programa da era pós-colonial na segunda metade do século XX, um instrumento do avanço do imperialismo ocidental. Afirma que o desenvolvimento pressupõe um movimento linear e unidirecional de todas as nações na busca de um progresso técnico e econômico, medido por índices quantitativos como o Produto Interno Bruto (PIB) e o Índice de Desenvolvimento Humano (IDH), utilizados para comparar e hierarquizar países. E denuncia a promessa frustrada deste programa ocidental: o universalismo do progresso. Assumindo a insustentabilidade do crescimento econômico ilimi-

1 Autor de Encountering Development. 
tado, expressa no aumento das desigualdades e da pobreza e na degradação ambiental, o autor revela a "decepção semântica" na inclusão do termo "desenvolvimento" nos Objetivos do Desenvolvimento Sustentável das Nações Unidas (p. 13).

Ainda nos textos introdutórios são expostos os critérios estabelecidos pelos organizadores para selecionar as visões de mundo e práticas apresentados na obra como alternativas ao desenvolvimento: os meios de produção econômica e reprodução social são controlados de forma justa? Todas as pessoas têm acesso a modos de vida significativos? As discriminações de gênero, classe, etnicidade, casta e sexualidade estão sendo extintas? Paz e não-violência estão difundidas na vida comunitária? (p. 19)

Os organizadores manifestam a intenção de repolitizar o debate sobre a transformação socioecológica, enfatizando sua multidimensionalidade, e convidam para um processo de decolonização intelectual, emocional, ética e espiritual. Expõem seu comprometimento com a democracia, descrita como um processo permanente de radicalização, que deve abranger todas as áreas da vida, e culminar numa democracia planetária (p. 21), opondo-se ao modelo da democracia representativa liberal.

As críticas à modernidade permeiam toda a obra, assim como às concepções que a acompanham, principalmente o individualismo, livre mercado, secularismo e liberalismo econômico. Os autores problematizam também a ideia universalista de ciência como verdade inquestionável e precursora do progresso ocidental, assim como o antropocentrismo e a visão dualista do mundo, defendendo a democracia do conhecimento e a diversidade cultural.

Além das críticas e da ruptura com o sistema vigente, a obra propõe oferecer possibilidades na "busca por um mundo ecologicamente sábio e socialmente justo" (p. 23). De acordo com os organizadores, as alternativas às concepções ocidentais hegemônicas podem emergir das margens do colonialismo e do capitalismo. Ainda que reconheçam a importância das teorias marxiana e marxistas, os organizadores defendem complementá-las com as contribuições feministas e ecologistas, "assim como com as imaginações que emanam das imaginações do sul do globo, incluindo os ideais de Gandhi” (p. 24). Reforçando as críticas de Sachs, os autores classificam a Agenda 2030 da ONU como "capitalismo verde", por não considerar as causas estruturais dos problemas socioambientais, manter a subserviência ao capital privado sem controle social, sujeitar a cultura, a ética e a espiritualidade às forças econômicas e evidenciar o crescimento econômico como motor do desenvolvimento (p. 26-27).

A organização da obra, dividida em três partes, também reflete as concepções que alicerçam sua construção. A primeira é intitulada Development and its crises: global experiences. Traz textos curtos de um pesquisador-ativista de cada um dos cinco continentes para refletir 
sobre o desenvolvimento: Nnimmo Bassey (África), Vandana Shiva (Ásia), Jose Maria Tortosa (Europa), Phil McMichael (América do Norte), Kirk Huffman (Oceania) e Maristella Svampa (América do Sul). Os autores desta seção reforçam a oposição ao modelo de desenvolvimento baseado em métricas do PIB e às políticas econômicas de organizações internacionais, como o Banco Mundial, o Fundo Monetário Internacional (FMI), além de pautas de movimentos sociais e visões de mundo de contextos culturais específicos. Diferencia-se o texto de Svampa, intitulado The Latin American Critique of Development, que apresenta as perspectivas críticas latino-americanas, mencionando tanto a sociedade de consumo do economista brasileiro Celso Furtado na década de 1970 até os conceitos que fazem parte do cenário epistemológico pós-desenvolvimento, como bem viver, bens comuns, entre outros.

A segunda seção da obra é intitulada Universalizing the world: reformist solutions. Como o próprio título indica, traz concepções consideradas soluções reformistas, que contribuem para a manutenção do status quo do Norte Global. Estas noções buscam conciliar a sustentabilidade com os interesses do sistema capitalista, por meio da mercantilização da natureza, da manutenção do crescimento econômico e da adoção da pauta neoliberal. Algumas têm em comum a crítica a ideias valorizadas pela ideologia neoliberal, como a noção de eficiência (também discutida em um verbete próprio) e a defesa da tecnologia como um fim em si mesma - evidenciada em "Ferramentas digitais", que alerta que seus usos não prescindem de um questionamento das condições de sua produção e seus efeitos socioambientais (p. 39).

Dentre as dezessete concepções classificadas como reformistas, estão "Desenvolvimento sustentável", "Cidades inteligentes", "Economia circular", "Economia Verde", "Neoextrativismo" e "BRICS". Este último, de autoria de Ana Garcia e Patrick Bond, é descrito como um bloco com potencial para confrontar a hegemonia ocidental, mas que acomoda projetos de elites nacionais e corporações multinacionais, seguindo políticas econômicas neoliberais.

A última seção da obra é denominada $A$ people's pluriverse: transformative initiatives, que, de acordo com os organizadores, tem a pretensão de desconstruir o desenvolvimento por meio de uma matriz de iniciativas. Traz oitenta e cinco concepções alinhadas a visões de mundo e práticas de comunidades indígenas, campesinas e pastorais, movimentos feministas, ambientais e de comunidades urbanas.

Essa matriz de iniciativas destaca-se pela ampla variedade. Algumas trazem concepções provenientes de contextos culturais específicos, como "Kametsa Asaike" (do povo ashaninka), "Kawsak sacha" (dos povos nativos amazônicos), "Hurai” (do povo chinês Tuva), "Prakritik Swaraj" (da filosofia indiana), "Minobimaatisiiwin" (das culturas Cree e Anishinaabe) e "Kyosei” (um conceito japonês). Já outras são oriundas de visões das maiores religiões no mun- 
do, expostas em "Ecoteologia cristã", "Ética islâmica", "Hinduísmo e transformação social", "Religiões chinesas", "Budismo e compaixão baseada em sabedoria”, "Tikkun Olam judaico", “Teologia da libertação", "Ibadismo" e "Visão de mundo Tao".

Destacam-se, pelo menos, três conceitos que defendem a existência coletiva, em oposição ao individualismo moderno: "Comunalidade", "Convivialismo" e "Convivialidade". Algumas noções fazem parte do vocabulário corrente nos meios de comunicação, como "Agroecologia", "Ecovilas", "Soberania alimentar" e "Software livre", e outras mais alinhadas às esferas econômica e política, articuladas ou não a contextos locais, como "Arbitragem para a dívida externa", "Democracia direta", "Decrescimento", "Economia democrática no Curdistão", "Ecossocialismo", "Democracia ecológica radical”, "Economia de solidariedade social", "Pós-economia", "Produção negentrópica", "Produção liderada por trabalhadores".

A obra inclui verbetes dedicados a movimentos feministas do Sul global e aos estudos de gênero, como "Ecofeminismo", "Feminismos latinoamericanos e caribenhos" e "Feminismos do Pacífico". Estes dois últimos, significativamente no plural, apontam a intenção de compreender a variedade de configurações dos feminismos, opondo-se à visão homogeneizante de "mulher universal" da vertente ocidental e liberal.

À primeira vista, alguns títulos chamam a atenção por sua generalidade, como "pedagogia" e "revolução". Mas a leitura desvela suas propostas em (re)definir as bases teóricas destas noções no cenário pós-desenvolvimento. Em "Pedagogia", de autoria de Jonathan Dawson, encontra-se uma crítica às demandas neoliberais para os sistemas educacionais e a adoção da ideia de comunidade de aprendizagem, inspirada na obra de Paulo Freire, que propõe um rompimento com a relação hierarquizada entre professor e aluno e com a concepção unilateral do processo de ensino-aprendizagem (p. 271). Já o novo sentido de "Revolução", escrito por Eduardo Gudynas, passa pelo questionamento radical do conceito de desenvolvimento e pela superação da modernidade, levando a mudanças significativas na estrutura social, que, segundo o autor, nem o capitalismo nem o socialismo puderam realizar (p. 293).

Os textos curtos cumprem a função de apresentar aos leitores as visões alternativas, servindo como um ponto de partida para uma pesquisa mais profunda. Essa proposta não permite, no entanto, compreender as possíveis incoerências ou contradições dessas noções ou práticas. Por exemplo, o verbete "Direitos Humanos", escrito por Miloon Kothari, não problematiza a lógica ocidental e os paradoxos destas concepções (p. 200). Mas algumas exceções podem ser destacadas. No verbete "Hinduísmo e transformação social", a autora Vasudha Narayanan reconhece que os hindus enfrentam desafios para combater a desigualdade social e a degradação ambiental, e admite que a religião, por vezes, é um impeditivo para o combate a estes problemas 
(p. 199).

O livro termina com um Postscript que convida os leitores a participarem da The Global Tapestry of Alternatives, que procura criar redes de solidariedade e alianças entre as alternativas ao modelo hegemônico. Refletindo sobre a noção zapatista de pluriverso a partir da obra, é possível reconhecer que é urgente e constitui um grande desafio elencar as noções e práticas que orientam a formação deste mundo em que cabem outros mundos.

\section{REFERÊNCIA}

1. KHOTARI, Ashish et al. Pluriverse: a post-development dictionary. Nova Delhi: Tulika Books, 2019.

Viviane Kraieski de Assunção

Professora do Programa de Pós-Graduação em Ciências Ambientais da Universidade do Extremo Sul Catarinense, Criciúma, Santa Catarina, Brasil. Doutora e mestre pelo Programa de Pós-Graduação em Antropologia Social (PPGAS) da Universidade Federal de Santa Catarina. Realizou estágio pós-doutoral na Vrije Universiteit Amsterdam. ID. ORCID: https:// orcid.org/0000-0003-0118-2486. E-mail: vivianekraieski@gmail.com. Colaboração: Pesquisa bibliográfica, Redação, Revisão.

Andréia Gimenes Amaro

Doutoranda do Programa de Pós-Graduação em Ciências Ambientais da Universidade do Extremo Sul Catarinense, Criciúma, Santa Catarina, Brasil. ID ORCID: https://orcid. org/0000-0001-9482-8084. E-mail: andreiagimenespmc@gmail.com. Colaboração: Pesquisa bibliográfica, Redação, Revisão. 